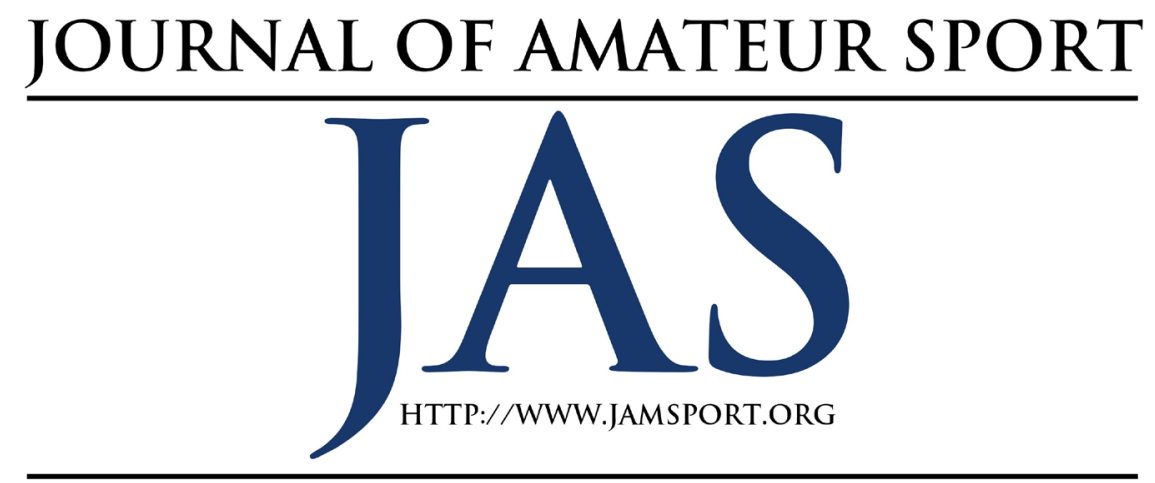

\title{
Quality of Life Is Lowest Among Female Athletes at the Community College Compared to University Sport Levels
}

\author{
Kaila Vento ${ }^{1}$ \\ Carly Graff ${ }^{2}$ \\ Jessica Bryant ${ }^{2}$
}

\author{
Megan N. Miller ${ }^{2}$ \\ Cailey Olono ${ }^{2}$ \\ Heidi Lynch ${ }^{2}$
}

\section{Arizona State University \\ ${ }^{2}$ Point Loma Nazarene University}

Quality of life (QOL) is essential for sport and academic performance, personal satisfaction, and general health. This study aimed to examine the QOL of female athletes at the NCAA Division I, NCAA Division II, NJCAA Division II, and student club sport levels. This cross-sectional study included $\mathrm{N}=159$ female athletes to complete a personal demographics and World Health Organization Quality of Life- Brief (WHOQOL-BREF) assessment. The primary QOL, including physical, mental, social relationships, and environmental health domains and total scores, were analyzed using Kruskal-Wallis tests. NCAA DI had a higher total QOL score than NJCAA $(p<0.001)$ and NCAA DII and NJCAA athletes $(p<0.05)$. Likewise, NCAA DI had higher physical health scores than NCAA DII and NJCAA DII athletes, and club athletes higher than NCAA DII, $p<0.001$. Lower mental health scores were found for NJCAA and club athletes compared to NCAA I, $p<0.01$, and NCAA II, $p=0.02$, athletes. NJCAA athletes had lower environmental health than NCAA DI and DII sports athletes, $p=0.05$. No differences were found for the social relationships domain, $p=0.61$. In conclusion, collegiate female athletes' QOL warrants improved wellness services, especially at the NJCAA level.

\section{ssessing the quality of life of $\mathcal{L}$ intercollegiate athletes better} overall health, supports athletic departments' decisions in resource allocation and policy reforms, and initiates proactive measures in reducing mental and physical ailments after ceasing competitive athletics (Filbay et al., 2019; Gentner, Wrisberg, \& Lounsbury, 2011; Royal \& Rossi, 1993). Sport participation positively influences and improves one's quality of life (Maher 
et al., 2013; Omorou et al., 2013; Rodríguez, Látková, \& Sun, 2008). Participating in sports helps develop physical strength and coordination, boosts self-esteem, provides interpersonal connection, and engages individuals in meaningful activities, contributing to life quality. Quality of life (QOL) refers to the domains concerning physical and mental well-being, along with social interactions and environmental surroundings (Diener, 2000; Gentner, Wrisberg, \& Lounsbury, 2011; Heller, Watson, \& Ilies, 2004). For example, strength training to increase muscle mass (physical), reduced stress after a satisfying practice (mental), enjoying teammates' company off and on the field (social), and access to sports facilities (environment) may add to an athlete's QOL. QOL is a positive affective state, in which the above domains are perceived to be meeting the needs of the individual based on satisfaction of current circumstances (Gentner, Wrisberg, \& Lounsbury, 2011). To sustain an athlete's QOL, specific necessities must be fulfilled to perform daily living, afford personal growth, and reap the benefits sports participation has to offer.

The QOL theory is derived from Maslow's Hierarchy of Needs, including physiological (e.g., food, shelter, clothing), safety (e.g., security, health, resources), belonging (e.g., connection, friendship, intimacy), esteem (e.g., respect, strength, recognition), and self-actualization (e.g., achieving one's fullest potential) (Sirgy, 1986). As the lower-order physiological and safety needs are met, progression towards belonging, esteem, and self-ac- tualization can be obtained, ultimately improving QOL. Maslow's Hierarchy of Needs is a well-established theory and has served as the model for QOL regarding patients with dementia (Schölzel-Dorenbos, Meeuwsen, \& Olde Rikkert, 2010), resident physicians (Hale et al., 2019), and collegiate athletics (Brunet et al., 2013).

Organized sports contribute to meeting athletes' needs while enhancing their QOL (Snedden et al., 2019). Athletic departments may provide housing, meals, and healthcare, while sports bring opportunities to build friendships, confidence, and self-fulfillment (Kim et al., 2020). Athletic departments supplementing basic living and safety resources could allow athletes to focus on intangible valuables obtained in sports participation (belongingness and esteem) and strive towards self-actualization. The higher-level organized sports, such as collegiate athletics, has shown benefits beyond physical activity levels, perhaps due to the infrastructure, regulations, and governing body to instate resources in place (Snedden et al., 2019). Thus, collegiate athletic departments play a critical role in ensuring athletes' basic needs are met and mitigating adverse wellness consequences.

Yet, even within collegiate athletics, QOL variances between male and female athletes have been recorded (Boldt et al., 2018; Gulliver et al., 2014; Snedden et al., 2019; Yang et al., 2007). Gulliver and colleagues (2014) found $46.4 \%(\mathrm{~N}=$ 224) of elite, college-aged Australian athletes reported symptoms of at least one mental health disorder, with females experiencing significantly higher general 
psychological distress and anxiety. As reported by Snedden et al. (2019), the Veteran's RAND (i.e., a brief health-related QOL survey) mental component scores were 2.5 units lower in National Collegiate Athletic Association (NCAA) Division I (DI) female athletes than males, with a two or greater unit difference to be clinically and socially relevant on a population level. The wide gap in mental health scores signals that female collegiate athletes are at a lower QOL than their male counterparts. Similarly, Yang and associates (2007) found female NCAA DI collegiate athletes $(n=90)$ had 1.32 higher odds of experiencing depression symptoms in comparison to male athletes. The intercollegiate sport (e.g., coach and performance demands, academics, and sports injuries) and traditional female stressors (e.g., menstrual regulation, body size, appearance) confronted by female athletes could lessen their QOL (Barnett \& Sharp, 2016; Lu et al., 2012; Selby, Weinstein, \& Bird, 1990; Vannuccini et al., 2020). Selby, Weinstin, and Bird (1990) found injuries and academic responsibilities were major stressors for male and female athletes. Yet, female athletes have significantly higher stress regarding diet, body image, and weight than males. Related to women's health, athletes with heavy menstrual bleeding were associated with having lower mental health scores $(39.7 \pm .8 .9$ vs $45.6 \pm 9.9)$ and higher perceived stress scores $(19.8 \pm .3 .2$ vs $17.0 \pm .4 .9)$ than those observed in female athletes with normal bleeding (Vannuccini et al., 2020). Thus, athletic departments must have available resources to address female athletes' unique stressors to minimize the risk of regression to lower-order needs and reduced sports satisfaction and participation.

Despite the comparative research between male and female athletes regarding mental health, there are few data available comparing female athletes' experiences at various collegiate levels of competition. The majority of studies have focused upon athletes' experiences at the DI level (Arnold \& Liu, 2020; Darvin, Cintron, \& Hancock, 2017; Kamusoko $\&$ Pembeton, 2013). However, female collegiate athletes competing at the NCAA, National Junior College Athletic Association (NJCAA), and student club sports (club) vary in sport commitment, training, and competition regulations (Dunn, 2013; Women's Sports Foundation [WSP], 2020). Likewise, the division categories (i.e., I, II, and III) and type of institution (i.e., private vs. public) could impact the health support and services provided within athletic departments (Lawrence, 2013), such as the number of private donations received and the sports competition wins awarded (Stinson \& Howard, 2008; Tomasini, Frye, \& Stotlar, 2004). Alumni donations, industry sponsorships, community partnerships, and national award winnings may influence the size of an athletic department's budget, and thus, allocation of resources (Stinson \& Howard, 2008; Tomasini, Frye, \& Stotlar, 2004). Given the popularity and revenue generated from male sports, such proceedings may be more inclined towards male athletes and less 
towards female athletes.

Moore (2016) demonstrated that student-athletes at DI and DII schools perceive having greater athletic services availability, including psychosocial services, compared to athletes at DIII schools. However, this study was not exclusively with female athletes, and an analysis of responses from only female athletes was not provided. Furthermore, this study did not compare athletes competing at the community college or club levels. Data on these populations are quite limited and not explicitly focused upon QOL.

Similarly, Keim and colleagues (2004) aimed to compare support service availability at two- and four-year colleges and investigated two-year college football coaches' perceptions of support services for student-athletes. Although the coaches reported awareness of support services offered, the authors did not compare these results to perceptions of support service availability offered at four-year institutions for student-athletes. Watson (2016) conducted a study of student-athletes' stress perceptions at community colleges and found that athletic identity contributed to perceived stress. As valuable as these studies are, they are not specifically about female athletes, nor do they directly compare student-athletes' experiences at the community college level with those at fouryear institutions.

In addition to the lack of data comparing female student-athlete experiences between two- and four-year universities, data about the QOL of club athletes are also sparse. Lifschutz (2012) has noted that athletes participating in club sports have less oversight from coaches and the university in general compared to varsity athletes at four-year universities. As such, the potential for risky behaviors, including hazing and excessive alcohol consumption, may be less likely to be detected. Bryant and Clement (2012) studied the coping mechanisms of seven female club sports leaders managing stress. They noted that pursuing emotional, social support, and avoidance were more commonly employed coping mechanisms than seeking information and instrumental social support (Bryant and Clement, 2012). While pursuing social support is undoubtedly a positive coping mechanism, avoidance raises concerns about unaddressed stress that may accumulate over time. Although helpful for understanding more about female club athletes, these studies do not compare these athletes' experiences with those of student-athletes at other institutions of different competition levels.

Therefore, there is a noticeable gap in the literature about female student-athletes' experiences across two- and fouryear institutional college and university levels, particularly concerning QOL. A QOL assessment could help athletic departments determine the females at risk of lower QOL, initiating movements towards improving the unmet resources within female programs (WSF, 2020).

Our objective was to ensure athletic departments are equipped with the proper resources to support all female athletes' needs and well-being. To the best 
of our knowledge, studies examining QOL among a diverse intercollegiate female athlete population are lacking. Thus, the purpose of this study was to examine the QOL of female athletes at the NCAA Division I (NCAA DI), NCAA Division II (NCAA DII), NJCAA Division II (NJCAA), and student club (club) sport levels. Based on Snedden et al.'s (2016) findings of health increasing with higher organized sports, we expected a lesser QOL among NJCAA athletes than those attending four-year universities.

\section{Participants}

$\mathrm{N}=159$ female athletes (NCAA DI, $\mathrm{n}=51$; NCAA DII, $\mathrm{n}=39$; NJCAA, $\mathrm{n}=$ 32; club, $\mathrm{n}=37$ ) participated in the study from the Phoenix and San Diego areas, as this is where the researchers are located. Data were dismissed for four NJCAA athletes due to incomplete questionnaires. Eligibility criteria included being a collegiate female student-athlete at least 18 years of age. All participants provided signed informed consent before study participation. The Institutional Review Boards approved the study at Arizona State University, Point Loma Nazarene University, and Maricopa County Community Colleges.

\section{Procedures}

After receiving IRB approvals, female athletes and their coaches/club presidents participating in the NCAA DI, NCAA DII, NJCAA, and club sport levels received study information from appropriate athletic personnel through emails and in-person briefs. An invitation to review a description of the study and informed consent was provided in the email and study flyers at briefs. Informed consent was obtained via paper and electronic formats; copies were given to all participants. Similarly, the personal demographics and QOL questionnaires were administered in-person within a designated laboratory or electronically via Qualtrics. Two methods of data collection were offered to be considerate of participants' time and privacy. The questionnaires were collected between October 2018, January-February 2019, and July-November 2019. Participants received a tangible or e-gift card for their contribution.

\section{Instruments}

This cross-sectional study involved two questionnaires: personal demographics and QOL assessment.

\section{Personal Demographics}

Participants' age, sport level, training hours per week, sport played, and years playing current sport were gathered.

\section{World Health Organization Quality of Life-Brief (WHOQOL-BREF)}

The WHOQOL-BREF consists of 26 items regarding physical (7 items), mental (6 items), social relationships (3 items), and environmental (8 items) health domains, as well as general health (2 items) (Skevington, Lotfy, \& O'Connell, 2004). Physical health entails mobility, medical needs, sleep, and daily functionality, whereas mental health pertains 
to personal satisfaction with appearance, happiness, and emotional state. Social relationships concern personal interactions, sexual satisfaction, and support from friends. Environmental health encompasses satisfaction with living conditions, transportation mode, access to health services and information, work areas, leisure activities, and surrounding built community. Questions are formatted on a 5-point Likert-scale inquiring 'how much,' 'how completely,' 'how often,' 'how good' or 'how satisfied' the participant felt in the last four weeks relative to the above health domains. The raw domain score range for mental, physical, social relationships, and environmental health are 7-35, 6-30, 3-15, and 8-40, respectively. It is standard practice to score the WHOQOL-BREF by transforming raw domain scores with a scale range of 0-100 using the following formula:

\section{Transformed Scale $=[($ Actual raw score - lowest possible raw score) $] \times 100$ \\ Possible raw score range}

Higher scores denote a higher QOL per domain. A total QOL score can be obtained by summing the raw domain scores, with a range of 24-120, and using the transformed scale calculation.

The WHOQOL-BREF is an abbreviated version of the WHOQOL-100 item QOL assessment. The WHOQOL-BREF demonstrates a high correlation to the WHOQOL-100 (Cronbach's alpha 0.89 and higher), good discriminant and content validity, and test-retest reliability (0.66-0.87) for all four domains (Whoqol Group, 1998). The WHOQOL-BREF has been used in female athletic running populations (Boldt et al., 2018) with a reported Cronbach's alpha for physical 0.87 , mental 0.87 , social relationships 0.69 , and environment 0.84 (Skevington, Lotfy, \& O'Connell, 2004). A Cronbach's alpha was calculated for this study and found physical 0.65 , mental 0.68 , social relationships 0.68 , and environmental 0.80 health domains, revealing questionable-to-acceptable internal consistency; the tally of all four QOL domains resulted in a Cronbach's alpha of 0.86 , suggesting acceptable internal consistency (Tavakol \& Dennick, 2011).

\section{Statistical Analysis}

All statistical analyses were conducted using SPSS (version 25, IBM Corp). Personal demographics are given as mean \pm standard deviation and sport participation percentages ( $\%)$ and frequencies (n). Sport level group sizes were not significantly different, $p=0.18$. The WHOQOL-BREF physical, mental, social relationships, and environmental health domain and total scores were not normally distributed; therefore, nonparametric tests were used. Total and domain scores are given as a median and interquartile range (IQR) with Kruskal-Wallis tests to detect sport-level differences. Effect sizes were calculated using eta squared $\left(\eta^{2}\right)$ for all sport-level findings. $\eta^{2}$ has a range from $0-1$ with $.01, .06$, and .14 representing small, medium, and large effect sizes (Fritz, Morris, \& Richler, 2012). 
Three particular WHOQOL-BREF questions of interest (i.e., 'Are you able to accept your bodily appearance?,' Q1; 'Have you enough money to meet your needs?, Q2; and 'How often do you have negative feelings such as blue mood, despair, anxiety, depression?,' Q3) were individually examined using the above statistical tests. These questions were highlighted as they may be particularly salient issues among an intercollegiate athletic population. All statistical analyses were performed with the significance level set at $p<0.05$.

\section{Results}

Participants (age, $19.7 \pm 1.3$ ) trained an average of $14.2 \pm 7.6$ hours per week. The top three participating sports in this study were track and field $(\mathrm{n}=35)$, soccer $(n=29)$, and cross-country $(n=18)$. Athletes played their respective sports for 9.3 \pm 5.2 years. Age, training hours per week, and years playing sports differed between the sport levels, $p<0.001$. Additional total and sport-level demographic information and $p$-values can be seen in Table 1.

\section{WHOQOL-BREF}

The median and IQR for total physical, mental, social relationships, and environmental health domain scores were 71.4 (60.7-82.1), 66.7 (58.3-75.0), 75 (66.7-91.7), and 75 (68.8-84.4), respectively. Significant sport-level differences were found for the physical $\left(\eta^{2}=0.29\right)$, mental $\left(\eta^{2}=0.08\right)$, and environmental $\left(\eta^{2}\right.$ $=0.07)$ health domains, $p<0.01$. NCAA DI had higher physical health scores than NCAA DII and NJCAA athletes, $p<0.001$; and club athletes higher than NCAA DII, $p<0.001$. Lower mental health scores were found for NJCAA and club athletes compared to NCAA DI $(p<0.01)$ and NCAA DII $(p=0.02)$ athletes. NJCAA athletes also had lower environmental health than NCAA DI and DII sports athletes, $p=0.05$. No significant differences were found for the social relationships domain, $p=0.61, \eta^{2}=$ 0.01. The median and IQR for the health domains per sport level can be seen in Table 2.

The median and IQR for total QOL scores were 71.9 (65.6-79.2). Significant sport-level differences were found for total QOL scores, $p=0.02, \eta^{2}=0.07$. NCAA DI had higher total QOL scores than NJCAA $(p<0.001)$ and NCAA DII and club athletes $(\phi<0.05)$. The median and IQR for total QOL scores per sport level can be seen in Table 2 .

\section{WHOQOL-BREF Questions Items of Special Interest}

The median and IQR for total WHOQOL-BREF special interest items Q1 (Are you able to accept your bodily appearance?), Q2 (Have you enough money to meet your needs), and Q3 (How often do you have negative feelings such as blue mood, despair, anxiety, depression?) were 4.0 (3.0-4.0), 4.0 (3.0-5.0), and 3.0 (2.0-4.0), respectively. Significant sport-level differences were found for Q2 $\left(\eta^{2}=0.06\right)$ and Q3 $\left(\eta^{2}=0.22\right), p<$ 0.001 . NJCAA athletes had lower monetary means (Q2) than NCAA DII athletes, $p<0.001$. Yet, NCAA DII athletes experienced more negative feelings (Q3) 


\section{Table 1}

Athlete Personal Characteristics

\begin{tabular}{|c|c|c|c|c|c|}
\hline & $\begin{array}{c}\text { All } \\
(\mathrm{N}=159)\end{array}$ & $\begin{array}{c}\text { NCAA DI } \\
(\mathrm{n}=51)\end{array}$ & $\begin{array}{l}\text { NCAA DII } \\
(\mathrm{n}=39)\end{array}$ & $\begin{array}{l}\text { NJCAA } \\
(n=32)\end{array}$ & $\begin{array}{c}\text { Club } \\
(n=37)\end{array}$ \\
\hline \multicolumn{6}{|l|}{ Demographics } \\
\hline $\operatorname{Age}^{a}$ & $19.7 \pm 1.3$ & $19.7 \pm 1.3$ & $\begin{array}{l}\text { mean } \pm \text { SD } \\
20.2 \pm 1.1\end{array}$ & $18.7 \pm 0.8^{* *}$ & $20.1 \pm 1.2$ \\
\hline Training hours per week ${ }^{\mathrm{b}}$ & $14.2 \pm 7.6$ & $15.0 \pm 6.1$ & $15.9 \pm 4.8$ & $17.2 \pm 8.6$ & $11.3 \pm 6.9^{* *}$ \\
\hline Sport years ${ }^{c}$ & $9.3 \pm 5.2$ & $10.6 \pm 3.7$ & $10.4 \pm 6.1$ & $9.6 \pm 4.1^{*}$ & $5.3 \pm 5.2^{* *}$ \\
\hline & & & $\%(\mathrm{n})$ & & \\
\hline \multicolumn{6}{|l|}{ Sport \% (n) } \\
\hline Basketball & $3(5)$ & $4(2)$ & $0(0)$ & $9(3)$ & $0(0)$ \\
\hline Cheerleading & $2(3)$ & $2(1)$ & $0(0)$ & $0(0)$ & $5(2)$ \\
\hline Cross Country & $11(18)$ & $10(5)$ & $31(12)$ & $3(1)$ & $0(0)$ \\
\hline Dance & $5(8)$ & $4(2)$ & $0(0)$ & $0(0)$ & $16(6)$ \\
\hline Dragon Boat & $1(1)$ & $0(0)$ & $0(0)$ & $0(0)$ & $3(1)$ \\
\hline Fencing & $1(2)$ & $2(1)$ & $0(0)$ & $0(0)$ & $3(1)$ \\
\hline Gymnastics & $1(2)$ & $2(1)$ & $0(0)$ & $0(0)$ & $3(1)$ \\
\hline Hockey & $1(2)$ & $0(0)$ & $0(0)$ & $0(0)$ & $5(2)$ \\
\hline Lacrosse & $5(8)$ & $14(7)$ & $0(0)$ & $0(0)$ & $3(1)$ \\
\hline Marching Band & $1(1)$ & $2(1)$ & $0(0)$ & $0(0)$ & $0(0)$ \\
\hline Quidditch & $2(3)$ & $0(0)$ & $0(0)$ & $0(0)$ & $8(3)$ \\
\hline Rugby & $4(7)$ & $6(3)$ & $0(0)$ & $0(0)$ & $11(4)$ \\
\hline Sailing & $1(1)$ & $0(0)$ & $0(0)$ & $0(0)$ & $3(1)$ \\
\hline Soccer & $18(29)$ & $0(0)$ & $31(12)$ & $25(8)$ & $24(9)$ \\
\hline Softball & $8(12)$ & $2(1)$ & $0(0)$ & $31(10)$ & $3(1)$ \\
\hline Swimming & $4(6)$ & $12(6)$ & $0(0)$ & $0(0)$ & $0(0)$ \\
\hline Track and Field & $22(35)$ & $24(12)$ & $38(15)$ & $25(8)$ & $0(0)$ \\
\hline Triathlon & $4(6)$ & $8(4)$ & $0(0)$ & $0(0)$ & $5(2)$ \\
\hline Ultimate Frisbee & $1(1)$ & $2(1)$ & $0(0)$ & $0(0)$ & $0(0)$ \\
\hline Volleyball & $4(6)$ & $4(2)$ & $0(0)$ & $6(2)$ & $5(2)$ \\
\hline Water Polo & $2(3)$ & $4(2)$ & $0(0)$ & $0(0)$ & $3(1)$ \\
\hline
\end{tabular}

Note. All numbers rounded to the nearest tenth; total values may not be exactly $100 \% .{ }^{a} \mathrm{NJCAA}$ significantly different

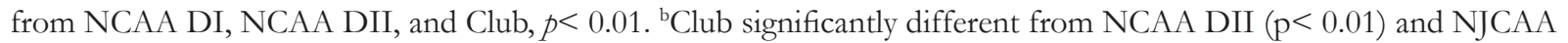
$(\mathrm{p}=0.01) .{ }^{\mathrm{c}} \mathrm{Club}$ significantly different from NCAA DI and DII, $\mathrm{p}<0.001 ;{ }^{\mathrm{c}} \mathrm{Club}$ significantly different from NJCAA, $p=$ 0.01 ; NJCAA significantly different from NCAA DII, $\mathrm{p}=0.03$.

$* P<0.05$.

$* * P<0.01$.

Journal of Amateur Sport Volume Seven, Issue Two Vento et al, 202158 
Table 2

Sport-level WHOQOL-BREF Scores

\begin{tabular}{|c|c|c|c|c|}
\hline & NCAA DI & NCAA DII & NJCAA & Club \\
\hline Domain & \multicolumn{4}{|c|}{ median (IQR) } \\
\hline Physical $^{a}$ & $78.6(71.4-89.3)$ & $57.1(53.6-71.4)^{* *}$ & $67.9(53.6-74.1)^{* *}$ & $75.0(71.4-82.1)$ \\
\hline Mental $^{\mathrm{b}}$ & $75.0(66.7-87.6)$ & $66.7(62.5-75.0)$ & $62.5(45.8-79.2)^{* *}$ & $66.7(52.1-75.0)^{* *}$ \\
\hline $\begin{array}{l}\text { Social Relation- } \\
\text { ships }\end{array}$ & $75.0(66.7-91.7)$ & $83.3(75.0-91.7)$ & $79.3(58.3-91.7)$ & $75.0(66.7-83.3)$ \\
\hline Environment ${ }^{c}$ & 78.1 (71.9-87.5) & $78.1(71.9-87.5)$ & $67.2(50.0-84.4)^{*}$ & $71.9(64.1-81.3$ \\
\hline Total & $77.0(68.6-85.4)$ & $69.8(64.6-78.1)$ & $67.2(52.3-81.8)$ & 69.8 (65.6-76.6) \\
\hline
\end{tabular}

Note. All numbers rounded to the nearest tenth; total values may not be exactly $100 \%$. ${ }^{a} \mathrm{NCAA}$ DI significantly different from NJCAA and NCAA DII, $p<0.001$; NCAA DII significantly different from Club, $p<0.001$; Club significantly

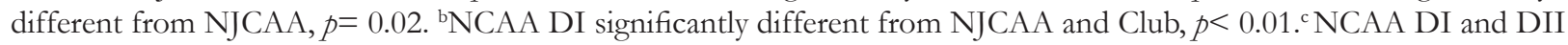
significantly different from NJCAA, $p=0.05$.

$* P<0.05$.

$* * P<0.01$.

Table 3

WHOQOL-BREF Questions Items of Special Interest

\begin{tabular}{|c|c|c|c|c|}
\hline & $\begin{array}{l}\text { NCAA DI } \\
(\mathrm{n}=51)\end{array}$ & $\begin{array}{c}\text { NCAA DII } \\
(\mathrm{n}=39)\end{array}$ & $\begin{array}{l}\text { NJCAA } \\
(n=32)\end{array}$ & $\begin{array}{l}\text { Club } \\
(\mathrm{n}=37)\end{array}$ \\
\hline $\begin{array}{l}\text { Question } \\
\text { Q1. Are you able to accept } \\
\text { your bodily appearance? } \\
\text { Q2. Have you enough money to }\end{array}$ & $4.0(3.0-5.0)$ & $\begin{array}{r}\text { medi } \\
4.0(3.0-4.0)\end{array}$ & $\begin{array}{l}\text { (QR) } \\
4.0(2.0-5.0)\end{array}$ & $4.0(3.0-4.5)$ \\
\hline $\begin{array}{l}\text { meet your needs?a } \\
\text { Q3. How often do you have } \\
\text { negative feelings such as blue } \\
\text { mood, despair, anxiety, depres- } \\
\text { sion?b }\end{array}$ & $4.0(3.0-5.0)$ & $2.0(2.0-3.0)^{* *}$ & $3.0(2.0-4.6)^{* *}$ & $3.0(3.0-4.0)$ \\
\hline
\end{tabular}

Note. All numbers rounded to the nearest tenth; total values may not be exactly $100 \%$. ${ }^{a} \mathrm{NCAA}$ DII significantly different from NJCAA, $p<0.001$. 'NCAA DII significantly different from NCAA DI, NJCAA, and Club, $\mathrm{p}<0.001$.

$* * P<0.01$.

than NCAA DI, NJCAA, and club athletes, $p<0.001$. No significant differences were found for Q1, $p=0.59, \eta^{2}=0.01$. The median and IQR for the special interest items Q1, Q2, and Q3 per sport level can be seen in Table 3 .

\section{Discussion}

The current study examined QOL among collegiate female athletes competing at varying sport levels. For the entire sample $(\mathrm{n}=159)$, the median QOL domain and total scores did not surpass 75 (scale range of $0-100$ ), indicating QOL did not attain the highest quarter of personal satisfaction. Overall median physical (71.4), mental (66.7), and social health (75.0) domain and total (71.9) 
scores were similar to those found by Correia et al. (2017), assessing QOL of college-aged female Brazilian ( $\mathrm{N}=32)$ volleyball athletes. Yet, environmental health (75.0) domain scores significantly differed compared to Correia et al. (2017) (59.5), suggesting the communities surrounding the colleges in our study more so met the needs of the athletes.

As expected, we found NJCAA athletes to have significantly lower physical, mental, and environmental health and total scores. It is plausible the availability of resources and athletic staff personnel may be limited within the NJCAA, potentially decreasing athletes' outlets for support (Author et al., Under Review; Lifschutz, 2012). The NCAA DI and club athletes appeared to have minor physical ailments, indicated by their higher scores. Yet, NCAA DII athletes had low physical scores, which could be related to the number of injuries noted by the research team and data collected during their in-season. NCAA DII and club athletes had exact median mental health scores (66.7), with NCAA DI nine points higher than their scores and 13 points more than NJCAA; the gap between mental health scores is alarming, warranting immediate attention. The NCAA DI and DII had identical environmental health scores, with club athletes within a close range. The transportation, campus layout, and access to facilities could be similarly designed. Social relationship scores for all sports levels were similar, suggesting their athletic teams could be fostering an inclusive and welcoming atmosphere. In addition to the differences in the
QOL health domains, we examined three questions of interest. Notably, NJCAA athletes reported the lowest score when answering monetary needs, indicating that they may be financially strained at the community colleges (Author et al., Under Review; Lifschutz, 2012). The NCAA DII athletes had the highest satisfaction of financial needs, which could relate to attending a private rather than a public university or college.

Interestingly, this did not correspond with responses to depressive feelings' frequency, as NCAA DII athletes reported the lowest scores. A possible explanation is that data collectors at the NCAA DII institution noted several injured athletes at the time information was gathered, supporting McAllister et al. (2001) and Gulliver et al. (2014) findings that injured athletes were more at risk of experiencing depression. Social relationship health scores were similar across sport levels, indicating female athletes felt a sense of belonging within their respective sports teams (Onağ \& Tepeci, 2014). Similarly, there were no significant differences between sport levels when evaluating body image satisfaction, with median responses for all levels were 4 (mostly) and 5 (completely). Though examining body image via different questionnaires, our sample had higher satisfaction than those reported by Barnett and Sharp (2016) using the Body Image Satisfaction Scale, yielding a $14.37 \pm 4.53$ score (range: $0-24)$. The high positive perception of body image witnessed across all sports levels was a welcome surprise given the accepted conception that female athletes 
have heightened diet and weight concerns.

Our findings highlight the QOL concerns witnessed among intercollegiate female athletes, especially at the community college level. Unmet foundational needs may negatively impact female athletes' sport satisfaction and participation as well as overall QOL. As such, we offer suggestions to assist athletes that are feasible to implement within athletic departments. Opening credit-hour internship opportunities for non-athlete graduate and undergraduate students studying health and wellness coaching (National Board of Health and Wellness Coaching [NDC-HWC], 2020), sport psychology (Association of Applied Sport Psychology [AASP], 2020), and dietetics (Commission of Dietetic Registration [CDR], 2020) may provide female athletes with the necessary services to assist with their general well-being, sport-induced stress, and nutritional concerns (Suando \& Miles, 2017). The four-year universities in this study have integrated a module amongst their scheduled courses related to sleep, nutrition, self-care, coping strategies, and scheduling services managed by the athletic departments to ensure accessibility and credibility of resources. We support having a 'wellness' module found amongst course modules as it could increase the use and notify when the module has been updated. To spur engagement and interaction, hosting in-person and virtual "Women Wellness Wednesday" events centered on female athletes' topics could initiate creativity, enjoyment, and a safe space to discuss intimate issues. Lastly, we highly recommend conducting mental and physical health screenings routinely throughout the academic year, as this could provide a significant opportunity to detect concerns and swiftly intervene before they progress.

The study was not without its limitations. Though sufficiently powered to detect differences (posthoc power analysis $=1.00$ ), our sample does not represent all intercollegiate female athletes, and the inclusion of the National Association of Intercollegiate Athletics (NAIA) and colleges representing each athletic Division (I-III) were missing. Additionally, an equal distribution of sports teams was not represented in our sample, making sports team comparisons unfeasible. Lastly, competition and non-competition seasons were not controlled when data collection took place, potentially influencing QOL results. The internal consistency of some QOL domains was less than acceptable; thus, interpretation of individual scores per domain is cautioned. Yet, the internal consistency of total QOL was acceptable. Future studies should include all intercollegiate athletic associations and respective divisions on a national level to examine QOL differences better. Additionally, data regarding the availability and quality of resources within athletic departments should be collected to mobilize service improvements. The current study provides an excellent basis for future qualitative researchers to conduct interviews with these athletes regarding their QOL and athletic department staff's perspectives 
on improving available resources. Likewise, experimental designs implementing innovative resources with female athletics programs are encouraged to utilize the Theory of Integration as a potential explanatory model, as the QOL framework is closely associated with a variety of student development models, allowing for a more robust application or interpretation of future results (Ventegodt, Merrick, \& Andersen, 2003).

In conclusion, QOL needs to be increased among female collegiate athletes, with community college athletes reporting the lowest scores. It is essential to provide useful resources to support female athletes' health and well-being needs, including mindfulness-based interventions, training for athletic staff, and support services hosted by the athletic department. Improving and maintaining the QOL of female athletes goes beyond their athletic college careers but promotes sports participation and personal longevity once retired.

\section{Acknowledgements}

We thank the student-athletes who participated and the athletic departments for their cooperation.

\section{Author Contributions}

$\mathrm{KV}$ and HL designed the study; data were collected and analyzed by KV, MM, $\mathrm{CG}$, and JB; KV and HL undertook data interpretation; $\mathrm{KV}$, HL, CO, MM, CG, and JB contributed to the manuscript preparation. All authors approved the final version of the paper.

\section{Funding Disclosures}

The study was funded by the Global Sport Institute at Arizona State University and by a grant from the Wesleyan Center at Point Loma Nazarene University.

\section{Conflict of Interest Disclosures}

None of the authors has any commercial or proprietary interest in any instrument used in this article. There was no conflict of interest.

\section{References}

Arnold, Z., \& Liu, H.-L. (Stella). (2020). The relationship between alcohol consumption, academic success, and athletic identity in colligate student-athletes. Journal of Amateur Sport, 6(2), 84-106. https://doi. org/10.17161/jas.v6i2.10570

Association of Applied Sport Psychology. (2020, August 25). Application forms. https://appliedsportpsych. org/certification/application-forms/ Barnett, M. D., \& Sharp, K. J. (2016). Maladaptive perfectionism, body image satisfaction, and disordered eating behaviors among US college women: The mediating role of self-compassion. Personality and Individual Differences, 99, 225 234. doi: 10.1016/j. paid.2016.05.004

Boldt, P., Knechtle, B., Nikolaidis, P., Lechleitner, C., Wirnitzer, G., Leitzmann, C., ... \& Wirnitzer, K. (2018). Quality of life of female and male vegetarian and vegan endurance runners compared to omnivores-results from the NURMI study (step 2). Jour- 
nal of the International Society of Sports

Nutrition, 15(1), 33. doi: 10.1186/

s12970-018-0237-8

Brunet, M. J., Atkins, M. W., Johnson, G. R., \& Stranak, L. M. (2013). Impact of intercollegiate athletics on undergraduate enrollment at a small, faithbased institution. Journal of Applied Sport Management, 5(1), 12. https:// trace.tennessee.edu/cgi/viewcontent. cgi? article $=1347 \&$ context $=$ jasm

Bryant, L. A., \& Clement, D. (2015). Coping strategies of female peer leaders participating in college club sports. Recreational Sports Journal, 39(1), 16 26. https:/ / doi.org/10.1123/ rsj.2013-0032

Commission on Dietetic Registration. (2020, September 4). RD examination eligibility requirements. https:/ / www.cdrnet.org/certifications/registered-dietitian-rdcertification.

Correia, R. F., Ribeiro, A. N., Barbieri, J. F., Brasil, D., Motta, L., Castaño, L. A., \& Salve, M. G. (2017). Quality of life levels in Brazilian elite female college volleyball players. International Journal of Sport Science, 7(1), 6-9. doi:10.5923/j.sports.20170701.02 Darvin, L., Cintron, A., \& Hancock, M. (2017). ¿ Por qué jugar? Sport socialization among Hispanic/Latina female NCAA division I student-athletes. Journal of Amateur Sport, 3(2), 27-54. https://journals.ku.edu/jams/ article/view/6460/6036

Diener, E. (2000). Subjective well-being: The science of happiness and a proposal for a national index. The American Psychologist, 55, 34-43.
doi:10.1037/0003-066X.55.1.34

Dunn, J. (2013). Should the playing field be leveled? Funding inequities among division I athletic programs. Journal of Intercollegiate Sport, 6, 44-51. doi:10.1123/JIS.6.1.44

Filbay, S., Pandya, T., Thomas, B., McKay, C., Adams, J., \& Arden, N. (2019). Quality of life and life satisfaction in former athletes: a systematic review and meta-analysis. Sports Medicine, 49(11), 1723-1738.https://doi. org/10.1007/s40279-019-01163-0

Fritz, C. O., Morris, P. E., \& Richler, J. J. (2012). Effect size estimates: current use, calculations, and interpretation. Journal of Experimental Psychology: General, 141(1), 2-18. doi:10.1037/ a0024338

Gentner, N., Wrisberg, C. A., \& Lounsbury, J. (2011). The athlete life quality scale: Development and psychometric analysis. Athletic Insight Journal, 3, 77-94. https:/ / www.researchgate.net/publication/286707757_The_athlete_life_ quality_scale_Development_and_psychometric_analysis

Gulliver, A., Griffiths, K. M., Mackinnon, A., Batterham, P. J., \& Stanimirovic, R. (2014). The mental health of Australian elite athletes. Journal of Science and Medicine in Sport, 18(3), 255-261. doi: 10.1016/j.jsams.2014.04.006 Hale, A. J., Ricotta, D. N., Freed, J., Smith, C. C., \& Huang, G. C. (2019). Adapting Maslow's hierarchy of needs as a framework for resident wellness. Teaching and learning in medicine, 31(1), 109-118. https://doi.org/1 
$0.1080 / 10401334.2018 .1456928$

Heller, D., Watson, D., \& Ilies, R. (2004). The role of person versus situation in life satisfaction: A critical examination. Psychological Bulletin. doi: 10.1037/0033-2909.130.4.574

Keim, M. C., \& Strickland, J. M. (2004). Support services for two-year college student-athletes. College Student Journal, 38(1). https://go-galecom.ezproxy1.lib.asu.edu/ps/i. do? $\mathrm{p}=\mathrm{CWI} \& \mathrm{u}=$ asuniv\&id $=$ GALE $\%$ 7CA115034773\&v $=2.1 \& i t=r$

Kim, M., Oja, B. D., Kim, H. S., \& Chin, J. H. (2020). Developing student-athlete school satisfaction and psychological well-being: The effects of academic psychological capital and engagement. Journal of Sport Management, 34(4), 378-390. https://doi. org/10.1123/jsm.2020-0091

Kamusoko, S. D., \& Pemberton, C. L. A. (2013). Student-athlete well-being and persistence: An in-depth look at student-athlete perceptions. Journal for the Study of Sports and Atbletes in Education, 7(1), 41-61. https://doi.org/10.1 179/1935739713Z.0000000003

Lawrence, H. (2013). The impact of intercollegiate athletics financial inequalities. Journal of Intercollegiate Sport, 6(1), 25-43. https://pdfs.semanticscholar.org/9b36/1db016aba4b030a2 9339846c934879147fd0.pdf

Lifschutz, L. (2012). Club sports: Maximizing positive outcomes and minimizing risks. Recreational Sports Journal, 36(2), 104-112. https://doi. org/10.1123/rsj.36.2.104

Lu, F., Hsu, Y., Chan, Y., Cheen, J., \&
Kao, K. (2012). Assessing college student athletes' life stress: Initial measurement development and validation. Measurement in Physical Education and Exercise Science, 16(4), 254-267. doi: 10.1080/1091367X.2012.693371

Maher, J.P., Doerksen, S.E., Elavsky, S., Hyde, A.L., Pincus, A.L., Ram, N., \& Conroy, D.E. (2013). A daily analysis of physical activity and satisfaction with life in emerging adults. Health Psychology, 32, 647-656. doi:10.1037/ a0030129

Moore, M. A. (2016). Do psychosocial services make the starting lineup? Providing services to student-athletes. Journal of Amateur Sport, 2(2), 5074. https://pdfs.semanticscholar.org/ fe1e/3a4a83ccbbb89804d3c4c40bfff1b9543c80.pdf

National Board-Certified Health and Wellness Coach. (2020, August 24). Become a national board-certified health and wellness coach. https:// nbhwc.org/become-a-board-certifiedcoach/

Omorou, Y.A., Erpelding, M., Escalon, H., \& Vuillemin, A. (2013). Contribution of taking part in sport to the association between physical activity and quality of life. Quality of Life Research, 22, 2021-2029. doi: 10.1007/ s11136-013-0355-3

Onağ, Z., \& Tepeci, M. (2014). Team effectiveness in sport teams: The effects of team cohesion, intra team communication and team norms on team member satisfaction and intent to remain. Procedia-Social and Behavioral Sciences, 150, 420-428. doi: 10.1016/j. 
sbspro.2014.09.042.

Royal, M. A., \& Rossi, R. J. (1993). A comparative approach to assessing the quality of life of intercollegiate athletes. Social Indicators $\mathrm{Re}$ search, 29(3), 317-330. https:/ /www. jstor.org/stable/pdf/27522701. pdf?casa_token $=\mathrm{mfnOv} 4 \mathrm{XKFjI}-$ AAAAA:B7fNSdBRP48HFmzl-9CZp_doKnX_K5WYgbaa-HDU5PoMO9LDI2YMcyObpKkbzRyKB4n5XQ3kPiEI4xAQZgboo1NbX_ QpaXF-3zeEN1-lzsj_5YOXcA Schölzel-Dorenbos, C., Meeuwsen, E., \& Olde Rikkert, M. (2010). Integrating unmet needs into dementia health-related quality of life research and care: Introduction of the Hierarchy Model of Needs in Dementia. Aging \& Mental Health, 14(1), 113-119. https:// doi.org/10.1080/13607860903046495

Selby, R., Weinstein, H. M., \& Bird, T. S. (1990). The health of university athletes: attitudes, behaviors, and stressors. Journal of American College Health, 39(1), 11-18. https:/ / doi.org/ 10.1080/07448481.1990.9936208

Simon, J., \& Docherty, C. (2014). Current health-related quality of life is lower in former Division I collegiate athletes than in non-collegiate athletes. The American Journal of Sports Medicine, 42(2), 423-429. doi: $10.1177 / 0363546513510393$

Sirgy, M. J. (1986). A quality-of-life theory derived from Maslow's developmental perspective: 'Quality' is related to progressive satisfaction of a hierarchy of needs, lower order and higher. American Journal of Economics and Sociology, 45(3), 329-342. https:// doi.org/10.1111/j.1536-7150.1986. tb02394.x

Skevington, S. M., Lotfy, M., \& O’Connell, K. 2. (2004). The World Health Organization's WHOQOL-BREF quality of life assessment: psychometric properties and results of the international field trial. A report from the WHOQOL group. Quality of Life Research, 13(2), 299-310. doi: 10.1023/B: QURE.0000018486.91360.00

Snedden, T. R., Scerpella, J., Kliethermes, S. A., Norman, R. S., Blyholder, L., Sanfilippo, J., ... \& Heiderscheit, B. (2019). Sport and physical activity level impacts health-related quality of life among collegiate students. American Journal of Health Promotion, 33(5), 675-682. doi: 10.1177/0890117118817715

Stinson, J. L., \& Howard, D. R. (2008). Winning does matter: Patterns in private giving to athletic and academic programs at NCAA Division I-AA and I-AAA institutions. Sport Management Review, 11(1), 1-20. doi: 10.1016/ S1441-3523(08)70101-3

Suando, L. E., \& Miles, C. M. (2017). Mental health services in NCAA Division I athletics: A survey of head ATCs. Sports Health, 9(3) 262-267. doi: $10.1177 / 1941738116679127$

Tavakol, M., \& Dennick, R. (2011). Making sense of Cronbach's alpha. International Journal of Medical Education, 2, 53-55. doi: 10.5116/ijme.4dfb.8dfd Tomasini, N., Frye, C., \& Stotlar, D. (2004). National collegiate athletic association corporate sponsor objec- 
tives: are there differences between divisions IA, I-AA, and I-AAA?. Sport Marketing Quarterly, 13(4). https://web.a.ebscohost.com/abstract?direct $=$ true\&profile $=$ ehost $\&$ scope $=$ site\&authtype $=$ crawler\&jrn$1=10616934 \& A N=15270036 \& \mathrm{~h}=\mathrm{sSz}-$ 1VDJxnOA\%2bqjhMSV7\%2bcu5gOdNcATV0kvLfNFyUmlYDatu2GWbPydILYKZ8f806JJdgacuU4WE4mZLbW8aA1 $w^{0} \% 3 \mathrm{~d} \% 3 \mathrm{~d} \& \mathrm{crl}=$ c\&resultNs $=$ Admin WebAuth\&resultLocal $=$ ErrCrlNotAuth\&crlhashurl=login. aspx $\% 3$ fdirect $\% 3$ dtrue $\% 26$ profile $\% 3$ dehost $\% 26$ scope $\% 3$ dsite $\%$ 26authtype $\% 3$ dcrawler $\% 26 j$ irn$1 \% 3 \mathrm{~d} 10616934 \% 26 \mathrm{AN} \% 3 \mathrm{~d} 15270036$ Vannuccini, S., Fondelli, F., Clemenza, S., Galanti, G., \& Petraglia, F. (2020). Dysmenorrhea and heavy menstrual bleeding in elite female athletes: Quality of life and perceived stress. Reproductive Sciences, 27(3), 888-894. doi: 10.1007/s43032-019-00092-7 Ventegodt, S., Merrick, J., \& Andersen, N. J. (2003). Quality of life theory I. The IQOL theory: An integrative theory of the global quality of life concept. The Scientific World Journal, 3 , 1030-1040. https://doi.org/10.1100/ tsw.2003.82
Watson, J. C. (2016). The effect of athletic identity and locus of control on the stress perceptions of community college student-athletes. Community College Journal of Research and Practice, 40(9), 729-738. https://doi.org/10.1080/10 668926.2015.1072595

Whoqol Group. (1998). Development of the World Health Organization WHOQOL BREF quality of life assessment. Psychological Medicine, 28(3), 551-558. https://depts.washington. edu/uwcssc/sites/default/files/ hw00/d40/uwcssc/sites/default/ files/WHO $\% 20$ Quality $\% 20$ of $\% 20$ Life $\% 20$ Scale $\% 20$ (WHOQOL).pdf

Women's Sports Foundation. (2020). Chasing equity: The triumphs, challenges, and opportunities in sports for girls and women. A Women's Sports Foundation Research Report,1-99.

https://www.womenssportsfoundation. org/wp-content/uploads/2020/01/ Chasing-Equity-Full-Report-Web.pdf Yang, J., Peek-Asa, C., Corlette, J. D., Cheng, G., Foster, D. T., \& Albright, J. (2007). Prevalence of and risk factors associated with symptoms of depression in Competitive collegiate student athletes. Clinical Journal of Sport Medicine, 17(6), 481-487. doi: 10.1097/ JSM.0b013e31815aed6b 